\title{
COMPUTERISED TURKISH VERSIONS OF TESTS FOR CENTRAL AUDITORY PROCESSING DISORDER
}

\author{
Meral Didem Turkyilmaz ${ }^{1}$, Suna Yilmaz ${ }^{2}$, Suha Yagcioglu ${ }^{3}$, Mehmet Yarali $^{1}$, Nagihan Celik ${ }^{4}$ \\ ${ }^{1}$ Hacettepe University Medical Faculty E.N.T Deaprtment, Audiology and Speech Pathology Unit \\ ${ }^{2}$ Ankara University Medical Faculty Paediatric Genetic Department, Audiology and Speech Pathology Unit \\ ${ }^{3}$ Hacettepe University Medical Faculty Biophysics Department \\ ${ }^{4}$ Private Rehabilitation Center, Audiology and Speech Pathology Unit
}

Corresponding author: Meral Didem Turkyilmaz, Hacettepe University Medical Faculty E.N.T Deaprtment, Audiology and Speech Pathology Unit, e-mail: didemcanatan@yahoo.com

\begin{abstract}
Background: To detect central auditory processing disorder (CAPD), a test battery is needed that probes the integrity of the central auditory nervous system and describes its response parameters. The audiologist needs to select a well-designed test battery that examines a variety of auditory performance areas. Computer-controlled adaptive tests are recommended because they maximise test efficiency and minimise floor and ceiling effects as well as minimising memory load. In order to increase test efficiency and minimise difficulties and training, we adapted computerised versions of the Frequency Pattern test and the Duration Pattern test.
\end{abstract}

Material and Methods: The present study was conducted at Hacettepe University, Turkey, in the Faculty of Medicine's Otorhinolarnygology Department, Audiology and Speech Pathology Unit. In total, 80 children (43 girls, 37 boys) aged between 7 years 0 months and 11 years 11 months were recruited. Each participant completed an informed consent form and a biographical survey prior to the tests. All tests were administered according to instructions at a comfortable listening level on a calibrated laptop computer which delivered a 'Frequency Pattern' test and a 'Duration Pattern' test.

Results: Normative test results are presented. Scores obtained by both tests were evaluated as percent scores for clinical study.

Conclusions: We adapted the computerised versions of the Frequency Pattern and Duration Pattern tests. Norm percent scores were obtained. We are continuing development of a computerised test battery that will include "gaps in noise" and "dichotic digits" tests using touch-screen protocols.

\section{КОМПЬЮТЕРИЗИРОВАННЫЕ ТУРЕЦКИЕ ВЕРСИИ ТЕСТОВ ПРИ ЦЕНТРАЛЬНОМ НАРУШЕНИИ ПЕРЕРАБОТКИ АУДИТОРНОЙ ИНФОРМАЦИИ}

\section{Резюме}

Введение: Для того, чтобы определить центральное нарушение переработки аудит орной информации (CAPD), необходима батарея тестов, которая исследует целостность центральной слуховой нервной системы и описывает ее параметры ответа. Аудиолог должен выбрать хорошо разработанную батарею тестов, которая исследует большое количество областей, затрагивающих работу слуха. Рекомендуются управляемые компьютером адаптивные тесты, так как они максимизируют эффективность тестов и минимизируют эффекты пола и потолка, кроме того уменьшая загруженность памяти. Чтобы увеличить эффективность тестов и уменьшить трудности и обучение, мы использовали компьютеризированные версии Теста Частоты Повторения и Теста Продолжительности.

Материал и Методы: Данное исследование проводилось в университете Хацеттеп, Турция, на Медицинском факультета, отделении Оториноларингологии, кафедре Аудиологии и Речевой Патологии. В общем приняло участие 80 детей (43 девочки, 37 мальчиков) в возрасте между 7 годами 0 месяцев и 11 годами 11 месяцев. Каждый участник заполнил форму информированного согласия и биографическую анкету до проведения тестов. Все тесты были проведены согласно инструкциям на соответствующем уровне громкости на калиброванном ноутбуке, который имел Тест Частоты Повторения и Тест Продолжительности.

Результаты: Представлены нормативные результаты тестов. Результаты, полученные в обоих тестах, были оценены в процентах для клинического исследования. 
Заключения: Мы использовали компьютеризированные версии тестов Частоты Повторения и Продолжительности. Результаты нормы были получены в процентах. Мы продолжаем развитие компьютеризированной батареи тестов, которая будет включать в себя тесты “промежутков в шуме” и “распознавания цифр” при использовании протоколов сенсорного экрана.

\section{VERSIONES TURCAS AUTOMATIZADAS DE PRUEBAS DE DESORDEN DEL PROCESAMIENTO AUDITIVO CENTRAL}

\section{Extracto}

Introducción: Para descubrir el desorden del procesamiento auditivo central (CAPD), una batería de pruebas es necesaria que sonde la integridad del sistema nervioso auditivo central y describe sus parámetros de respuesta. El audiólogo tiene que seleccionar una batería de pruebas bien diseñada que examina una variedad de áreas de rendimiento auditivo. Las pruebas adaptables controladas por el ordenador son recomendadas porque ellos maximizan la eficacia de prueba y reducen al mínimo los efectos de techo y suelo y también la carga de memoria. Para aumentar la eficacia de prueba y reducir dificultades y formación, adaptamos versiones automatizadas de la prueba de patrones de frecuencia y prueba de patrones de duración.

Material y Métodos: El estudio fue conducido en la universidad Hacettepe, Turquía, en la Facultad de medicina, el Departamento de Otorinolaringología, Unidad de Audiología y Daño de Habla. En total, participaron 80 niños (43 muchachas, 37 muchachos) de edad entre 7 años 0 meses y 11 años 11 meses. Cada participante completó una forma de consentimiento informado y una revisión biográfica antes de las pruebas. Todas las pruebas fueron administradas según instrucciones, a un nivel de escucha cómodo en un ordenador portátil calibrado que tuvo la prueba de Patrones de Frecuencia y prueba de Patrones de Duración.

Resultados: Los resultados de pruebas normativos son presentados. Resultados obtenidos por ambas pruebas fueron evaluados en por cientos para la investigación clínica.

Conclusiones: Adaptamos las versiones automatizadas de las pruebas de Patrones de Frecuencia y de Patrones de Duración. Resultados de norma fueron obtenidos en por cientos. Seguimos el desarrollo de una batería de pruebas automatizada que incluirá pruebas GIN (gaps in noise) y "dígitos dicóticos” usando protocolos de pantalla táctil.

\section{Background}

Some school-aged children who have hearing problems are described by their parents and teachers as being uncertain about what they hear, have difficulty listening in the presence of background noise, understanding rapid speech, and following oral instructions [1]. Yet some of these children's auditory thresholds are within normal limits. Listening problems result from an auditory processing deficit (APD), defective processing of auditory information in spite of normal auditory thresholds [2].

Broadly stated, central auditory processing (CAP) refers to the efficiency and effectiveness by which the central nervous system (CNS) utilises auditory information [3]. CAP disorder (CAPD) refers to the perceptual processing of auditory information in the CNS and the neurobiologic activity as demonstrated by poor performance in one or more of the auditory processing skills [3]. CAPD is best viewed as a deficit in the neural processing of auditory stimuli that may coexist with, but is not the result of, dysfunction in other modalities $[4,5]$. Thus, although many children with cognitive or language disorders may have difficulty processing spoken language, we should not automatically assume that a CAPD is the underlying cause of their difficulties without the demonstration of an auditory deficit through appropriate auditory diagnostic measures [5].

In 2005, the American Speech-Language Hearing Association (ASHA) approved its working group document on
CAPD [3]. The purpose of this document was to update the 1996 ASHA position statement and to guide audiologists in evaluation (i.e. selecting the appropriate tools to accurately make CAP evaluations) and intervention (i.e. selecting necessary therapy methods) of CAPD [6]. The purpose of a central auditory diagnostic test battery is to examine the integrity of the central auditory neural system and to determine the presence of a CAPD and describe its parameters $[1,2,7]$. To do this, the audiologist should examine a variety of auditory performance areas and select a well-designed test battery [1,7]. The audiologist needs the knowledge and skills necessary to perform the testing and they must consider listener variables: attention, auditory neuropathy, fatigue, hearing sensitivity, intellectual and developmental age, medications, motivation, motor skills, native language, language experience, response strategies, and visual acuity $[3,5,7]$. Also the design of the test instruments needs to take into account cognitive demands, floor and ceiling effects, learning/practice effects, linguistic demands, and suitable response modes [3,5,7].

In the light of these factors and variables, computer-controlled tests are recommended because they maximise test efficiency, minimise floor and ceiling effects, and minimise memory load [3]. To increase test effciency and motivation, and also to minimise training and difficulties in giving responses, we have converted the Frequency and Duration Pattern Tests [8] to a computerised form. The resulting Computerised Revised Frequency and Duration Pattern Tests allows acoustic stimuli to be presented via the 
Table 1. Age and gender distributions.

\begin{tabular}{|c|c|c|c|}
\hline \multicolumn{2}{|c|}{ Age (years) } & \multicolumn{2}{c|}{ Gender } \\
\hline & $\mathbf{N}$ & Boys & 8 \\
\hline $7: 0-7: 11$ & 14 & 8 & 7 \\
\hline $8: 0-8: 11$ & 15 & 10 & 9 \\
\hline $9: 0-9: 11$ & 20 & 7 & 9 \\
\hline $10: 0-10: 11$ & 16 & 6 & $\mathbf{4 3}$ \\
\hline $11: 0-11: 11$ & 15 & $\mathbf{3 7}$ & 9 \\
\hline
\end{tabular}

computer after which the participant responds by pressing the numeric key pad. We are also developing a touchscreen version. Details on the development, administration, and scoring system are described in the next section.

\section{Material and Methods}

The present study was conducted at the Hacettepe University, Turkey, in the Faculty of Medicine, Otorhinolarnygology Department, Audiology and Speech Pathology Unit.

\section{Subjects}

In total 80 children (43 girls, 37 boys) were recruited aged between 7 years 0 months and 11 years 11 months (see Table 1). Subjects were recruited through local schools and via the relatives or caregivers of inpatients and outpatients. They can be considered a representative sample of children from an average socio-economic background. Each participant completed the informed consent form and a biographical survey prior to the tests. The biographical survey was a series of questions regarding demographic information such as age, self-reported hand dominance, past medical history, and speech, language, hearing, and learning history. APD history was taken prior to commencing the tests and as far as possible to ascertain that all subjects had no APD complaints, were age appropriate for reading and language abilities, and were not experiencing any difficulties with school work. Participants were excluded if they had taken any drugs known to affect mental status, if they had neurological illness, major or minor brain injury, speech and language problems, or other health problems. Turkish was their native language. All subjects had normal hearing (thresholds better than or equal to $15 \mathrm{~dB}$ HL from $125 \mathrm{~Hz}$ to $8000 \mathrm{~Hz}$ bilaterally). All children were free of active otologic disease on the day of testing based on otoscopy and tympanometry with a present ipsilateral acoustic reflex at $1000 \mathrm{~Hz}$ and contralateral acoustic reflex at 500, 1000, 2000, and $4000 \mathrm{~Hz}$.

\section{Application procedures}

All subjects were tested while seated in a sound-treated room. All tests were administered according to the tester instructions at a comfortable listening level (55 dB SL relative to $1000 \mathrm{~Hz}$ ) on a calibrated laptop computer. Testing was not initiated until it was felt the subjects understood their task. Stimuli were presented through Sennheiser HD202 closed ear headphones. Presentation of stimuli to each ear

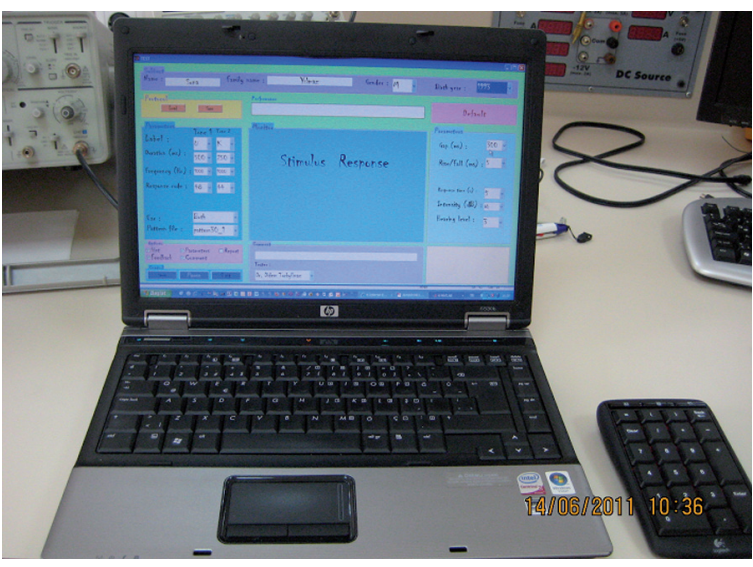

Figure 1. The test setup.

was randomised. All subjects were given practice/pre-test items, which were placed at the beginning of the test to ensure the task was understood. The subject had to push the numeric key pad after each stimulus in the practice test and in the Pattern 1 and Pattern 2 test sessions. After they passed 10 practice items, and indicated readiness to proceed, presentataion of Pattern 1 and then Pattern 2 commenced. The participants were given breaks at the end of completed tests to prevent fatigue. The procedure is shown in Figure 1.

\section{Development of test stimuli}

The Computerised Revised Frequency and Duration Pattern Tests [8] allow acoustic stimuli to be presented via computer to which the participant responds by pressing the numeric key pad. Frequency and Duration Pattern test stimuli were developed with MATLAB 7.10 software [9]. We had three pattern files: Pattern 1 (30 stimuli) and Pattern 2 (30 stimuli) and 10 randomly assigned trial patterns. The system included five functions: subject management, test procedures, list management, data management, and system settings.

1. Subject management: In this system, the tester is able to search, review, add, revise, and delete the subject's information. This information includes basic information as well as results.

2. List management: Using list management, testers can review, add, revise, and delete lists or items such as characters, key words, and sounds.

3. Test procedures: Protocol files can be adjusted. We implement learning, practice, and real test protocol files. Also the operator can make choices (including frequency and 
duration of stimuli), implement protocols, and save. Tones can be varied between $110 \mathrm{~Hz}$ and $1430 \mathrm{~Hz}$, have durations between 50 and $500 \mathrm{~ms}$, and be varied in intensity. Response codes can be adjusted to suit particular keys on the numeric key pad. Stimuli can be from both ears together or from left or right ears seperately. Interstimulus interval can be adjusted between 50 and $500 \mathrm{~ms}$, response time from 1 to $10 \mathrm{~s}(1000 \mathrm{~s}$ for training), and in intensity. Adjustments can be hidden, and feedback choice can be displayed, especially for the learning phase.

4. Data management: Results can be reviewed, searched, and exported. Results can be saved as a Microsoft Excel file for statistical analysis.

5. System setting: According to the test conditions and the preferences of the tester, adjustments can be made to the selection table, test mode, test-time interval, stimuli type, frequency, intensity, channel settings, parameters file, and threshold level.

6. Response mode: Subjects were instructed to press a wireless numeric key pad. Four indicator stickers were placed on the pad: "LOW" for low stimuli; "HIGH" for high stimuli; "SHORT" for short stimuli, and "LONG" for long stimuli. If there was any confusion regarding the appropriateness of a response the examiner asked the subject what they heard. During the practice session, subjects were checked to ensure the response pad was being appropriately handled. Total test time was slightly longer than other temporal processing measures - approximately 20 minutes for practice and evaluation of both ears.

7. Scoring: To score a correct answer, the participants had to give a correct response. Humming or a verbal response was not permitted. Reversals, omissions, and insertion of tones and sequential patterns were considered errors. With MATLAB, results can be reviewed, searched, and exported as an Excel file for statistical analysis. Every correct performance score is accepted as 0.33 and calculated as a percentage.

Auditory temporal processing and patterning tests assess the subject's ability to analyse acoustic events over time (e.g., sequencing and patterns, gap detection, fusion discrimination, integration). Temporal sequencing involves the perception and processing of the order in time of two or more auditory stimuli. Temporal sequencing can be assessed using the Frequency (Pitch) Pattern Test [8] and Duration Pattern Test $[8,10]$.

\section{Frequency Pattern Sequence Test}

The FPT was composed of 60 test sequences, each containing three tone bursts. In each sequence, two of the tone bursts are of the same frequency, whereas the third is different. The tones were combinations of $880 \mathrm{~Hz}$ for low frequency $(\mathrm{L})$ and $1122 \mathrm{~Hz}$ for high frequency $(\mathrm{H})$. Thus there were six possible combinations of three tone sequences (HHL, LHL, HLL, HLH, LHH, LLH). In the procedure, interstimulus interval was $300 \mathrm{~ms}$, duration was $500 \mathrm{~ms}$, and rise-fall time was $5 \mathrm{~ms}$. Response time was $5 \mathrm{~s}$.

\section{Duration Pattern Test}

The DPT was composed of 60 sequences containing three tone bursts. On this test, the frequency of the tones were maintained at $1000 \mathrm{~Hz}$ and the duration of the tones were varied [250 $\mathrm{ms}$ for short (S) and $500 \mathrm{~ms}$ for long (L)]. In each sequence, two of the three tones had the same duration, whereas the third was different. Thus there were six possible combinations of three tone sequences (LLS, LSL, LSS, SLS, SLL, SSL). In the procedure, rise-fall time was adjusted to $5 \mathrm{~ms}$. Response time was $5 \mathrm{~s}$.

Parameters of Frequency Pattern Sequence and Duration Pattern Test:

$\begin{array}{ll}\begin{array}{l}\text { Frequency Pattern } \\ \text { Sequence Test }\end{array} & \text { Duration Pattern Test } \\ \text { Low frequency: } 880 \mathrm{~Hz} & \text { Short duration: } 250 \mathrm{~m} \\ \text { High frequency: } 1122 \mathrm{~Hz} & \text { Long duration: } 500 \mathrm{~ms} \\ \text { ISI: } 300 \mathrm{~ms} & \text { ISI: } 300 \mathrm{~ms} \\ \text { Duration time: } 500 \mathrm{~ms} & \text { Frequency: } 1000 \mathrm{~Hz} \\ \text { Rise-fall time: } 5 \mathrm{~ms} & \text { Rise-fall time: } 5 \mathrm{~ms} \\ \text { Response time: } 6 \mathrm{~s} & \text { Response time: } 6 \mathrm{~s}\end{array}$

\section{Statistical analysis}

Data were analysed using SPSS for Windows 15.0 software. Descriptive statistics of measurements were calculated as mean \pm SD. The nonparametric Mann-Whitney U test was chosen because the number of subjects in the groups was small and several variables did not follow a normal distribution. The Mann-Whitney test was performed to test for differences in genders and age groups.

\section{Results}

\section{Descriptive data}

The descriptive data contains means and standard deviations for the Frequency Pattern Sequence Test (FPT) and the Duration Pattern Test (DPT) according to five age groups for 80 subjects.

The results (percent correct) for the two tests are shown in Table 2 for the five age groups 7 years to 11 years.

Using the Mann-Whitney test, we determined that there were no significant differences between male and female subjects in all groups. The test scores of FPT and DPT were not affected by gender.

Visual inspection of individual data seems to show an increase in test score with age for all age groups for both FPT and DPT tests (Figure 2). However, statistically there was only a significant relation in DPT test scores between the 7 years olds and 11 years olds $(p<0.05)$. The $p$ values are shown in Table 3 .

\section{Discussion and Conclusions}

This article provides normative data for the Frequency Pattern Sequence test (FPT) and the Duration Pattern test (DPT), which are the most frequently used behavioural tests for APD in Turkey. The participants were gathered from similar backgrounds and had normal pure tone thresholds, no middle ear disorders, and no history of learning difficulties. The results of the tests closely resembled the published 
Table 2. Percent scores for the two behavioural tests by ear [right ( $R$ ) and left $(L)$ ear] and age group.

\begin{tabular}{|c|c|c|c|c|c|c|c|}
\hline \multirow{2}{*}{ Age (years) } & \multicolumn{3}{|c|}{ Gender } & \multirow{2}{*}{ FPT-R (\%) } & \multirow{2}{*}{ FPT-L (\%) } & \multirow{2}{*}{ DPT-R (\%) } & \multirow{2}{*}{ DPT-L (\%) } \\
\hline & $\mathbf{n}$ & Boys $(n=37)$ & Girls $(n=43)$ & & & & \\
\hline 7:0-7:11 & 14 & 6 & 8 & $77.14 \pm 16.73$ & $73.06 \pm 17.93$ & $49.99 \pm 18.53$ & $48.32 \pm 19.01$ \\
\hline $8: 0-8: 11$ & 15 & 8 & 7 & $71.60 \pm 11.23$ & $73.83 \pm 12.22$ & $53.27 \pm 16.82$ & $53.83 \pm 17.16$ \\
\hline 9:0-9:11 & 20 & 10 & 10 & $79.21 \pm 17.76$ & $79.60 \pm 15.87$ & $65.48 \pm 14.09$ & $59.22 \pm 16.05$ \\
\hline 10:0-10:11 & 16 & 7 & 9 & $83.70 \pm 19.92$ & $87.40 \pm 18.34$ & $64.40 \pm 17.41$ & $70.95 \pm 18.85$ \\
\hline 11:0-11:11 & 15 & 6 & 9 & $89.33 \pm 11.22$ & $84.66 \pm 11.45$ & $75.33 \pm 15.20$ & $76.66 \pm 13.12$ \\
\hline
\end{tabular}

Table 3. Correlations between age and test performance based on 7 year old and 11 year old age groups.

\begin{tabular}{cccc}
\hline FPT-R (\%) & FPT-L (\%) & DPT-R (\%) & DPT-L (\%) \\
\hline 0.186 & 0.257 & $0.019^{\star}$ & $0.014^{*}$ \\
\hline
\end{tabular}

* $(p<0.05)$.

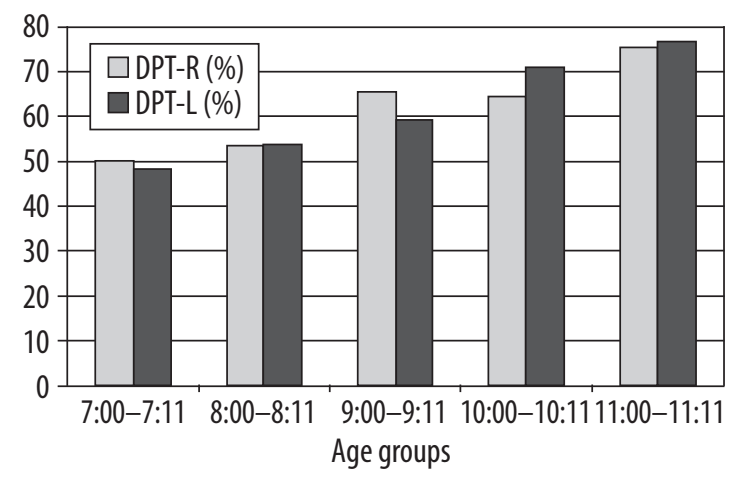

Figure 2. DPT test performance for right (R) and left (L) ears according to the five age groups.

normative data. Musiek's norms for FPT: for 8 years, L ear $40 \%$, R ear $40 \%$; for 9 years, L ear $65 \%$, R ear $65 \%$; for 10 years, L ear 72\%, R ear 72\% [14]. Kelly's norms for FPT test: for 7-8 years, L ear 71.02\%, R ear 72.62\%; for 9-10 years, L ear $85.32 \%$, $\mathrm{R}$ ear $87.77 \%$; for $11-12$ years, L ear $91.40 \%$, $\mathrm{R}$ ear $92.70 \%$ [15]. Stollman's norms for DPT: 6 years is 19\%, 7 years $47 \%$, 8 years $57 \%$, 10 years $79 \%$, and 12 years $90 \%$ [16]. All tests show an improvement in scores with age.

We did not find any gender differences in the FPT and DPT test scores in any age group. Stollman's results also support our gender results [16].

Visual inspection of individual data on FPT and DPT test scores shows an increase with age. Our data indicate that maturational effects play an important role up to age 11 years, which is in good agreement with the literature on the development of auditory processing abilities [15-18]. However, there was only a statistically significant relation in DPT test scores between 7 years and 11 years $(p<0.05)$. Our data suggest that the FPT shows no clear maturation from the age of 7 years.

Interpretation of central auditory test performance is guided by criterion referenced scores. The primary purpose of testing is to differentiate normal versus abnormal performance. For that purpose, the use of cut-off scores that are based on appropriate normative data can be used. Cut-off scores (e.g., in percent correct, percentiles, or standard scores) should be set at performance levels (e.g., $\sim 2$ or 3 standard deviations below the mean) to achieve the best balance between sensitivity and specificity $[19,20]$. We just implemented the computerised form and presented percent correct scores for FPT and DPT tests. In future, we are going to present cut-off scores.

In summary, we have developed a computer-based version of FPT and DPT tests. The reasons in favour of a computerised form are many $[3,5,11]$ but the following factors come into play. COGNITIVE STATUS: The child must have a normal IQ. Children with cognitive function in the lowaverage range cannot be reliably compared with cohorts. LANGUAGE STATUS: The child must be proficient in their language. All CAP tasks are administered in the native language and involve the presentation of degraded/altered speech materials. To complete these tasks, the child must have knowledge of the native language. HEARING STATUS: The child should have normal hearing bilaterally. SPEECH INTELLIGIBILITY: The child should not have a severe articulation disorder. Behavioral CAP tasks involve repetition of information (numbers, words, sentences). In a person with reduced speech intelligibility, it may be difficult to determine whether an incorrect response is a result of hearing the stimulus incorrectly or repeating the item incorrectly due to articulation issues. EMOTIONAL STATUS: The child should not be diagnosed with a severe emotional disorder. Children with severe emotional and/or behavioral disorders may have difficulty attending to or completing standardised testing $[3,5,11,12]$. In general, it is advisable to select the minimum number of tests necessary to provide the best overall sensitivity and specificity while, at the same time, assessing a representative sample of the major auditory processes [11]. Test measures should be carefully chosen so that they do not interject listener confounds as discussed above and allow for identification of patterns of auditory deficits for diagnostic and intervention purposes. The goal of an efficient behavioral 
central auditory test battery can be accomplished in 45 to 60 minutes $[3,5]$. Extending the central auditory evaluation beyond an hour may result in increased fatigue and attentional and/or motivational confounds.

Computer administration and scoring means that the above principles and factors can be accommodated. It increases test efficiency and motivation, minimises training, and reduces difficulties in response mode. Auditory perception requires precise and accurate processing of the timing elements of sound $[8,10,13]$, which is crucial to processing at the neuronal level of higher level speech and language
[15]. Technological developments in synthesised speech and the ability of computers to provide consistent stimuli in a repetitive manner have greatly increased the possibilities of diagnosis and intervention strategies on APD.

An obvious limitation of our study is the small number of subjects. We intend to recruit 80 normal subjects and at this point the data have been separated into five age groups. In future we are going to continue developing a computerised test battery including "gaps in noise" and "dichotic digits" tests with touch-screen test protocols. In addition, we will standardise our battery with cut-off scores.

\section{References:}

1. Emanual D: The auditory processing battery: survey of common practices. J Amer Acad Audiol, 2002; 13: 93-117

2. Yalçınkaya F, Keith R: Understanding auditory processing disorders. Turk J Pediatr, 2008; 50: 101-5

3. American Speech-Language-Hearing Association, (Central) Auditory Processing Disorders, Working Group on Auditory Processing Disorders, Technical report, 2005

4. Chermak GD, Musiek FE: Handbook of (central) auditory processing disorder: Auditory Neuroscience and Diagnosis Volume I. San Diego: Plural Publishing, 2007

5. Jerger J, Musiek F: Report of the consensus conference on the diagnosis of auditory processing disorders in school-aged children. J Ameri Acad Audiol, 2000; 11: 467-74

6. American Speech-Language-Hearing Association, Central auditory processing: Current status of research and implications for clinical practice. Am J Audiol, 1996; 5: 41-54

7. Erickson K: (C)APD testing and interpreting 101: Recommendations for audiologists, Presented in Audiology Online, 2008 from $h t t p: / / w w w$.audiologyonline.com/

8. Musiek FE: Frequency (pitch) and duration pattern tests. J Am Acad Audiol, 1994; 5: 265-68

9. MATLAB 7.10. The MathWorks, Inc., Massachusetts, U.S.A.

10. Musiek F, Baran J, Pinheiro M: Duration pattern recognition in normal subjects and patients with cerebral and cochlear lesions. Audiology, 1990; 29: 304-13

11. Chermak GD, Musiek FE: Central Auditory Processing Disorders: New Perspectives. San Diego: Singular Publishing Group, 1997
12. Philips DP: Central auditory system and central auditory processing disorders: some conceptual issues. Seminars in Hearing, 2002; 23(4): 251-62

13. Demanez L, Demanez JP: Central auditory processing assessment. Rev Laryngol Otol Rhinol, 2004; 125: 281-86

14. Musiek FE: The frequency pattern test: a guide. Hearing Journal, 2002, 55(6): 58

15. Kelly A: Normative data for behavioural tests of auditory processing for New Zealand school children aged 7 to 12 years. The Australian and New Zealand Journal of Audiology, 2007; 29(1): 60-64

16. Stollman M, Velzen E, Siemkens $H$ et al: Development of auditory processing in 6-to-12 year old children: a longitudinal study. International Journal of Audiology, Int J Audiol, 2004; 43(1): 34-44

17. Keith RW: Development and standardization of SCAN-A: test of auditory processing disorders in adolescents and adults. J Am Acad Audiol, 1995; 6: 286-92

18. Keith RW: Development and standardization of SCAN-C test for auditory processing disorders in children. J Am Acad Audiol, 2000; 11: 438-45

19. Musiek FE, Bellis TJ, Chermak GD: Nonmodularity of the CANS: implications for (central) auditory processing disorder. Am J Audiol, 2005; 14(2): 128-38

20. Shinn JB, Musiek FE: The auditory steady state response in individuals with neurological insult of the central auditory nervous system. J Am Acad Audiol, 2007; 18(10): 826-45 